\title{
EFFECT OF CITIZEN ACTION ON SUPPRESSION OF INVASIVE ALIEN LIZARD POPULATION: A CASE OF THE REMOVAL OF EUTROPIS MULTIFASCIATA ON GREEN ISLAND, TAIWAN
}

\author{
CHAO, R.-F. ${ }^{1}-$ LIN, T.-E. ${ }^{2 *}$ \\ ${ }^{I}$ Department of Leisure Management, I-Shou University \\ No.1, Sec. 1, Syuecheng Rd., Dashu District, Kaohsiung City, Taiwan, R. O. C. \\ (tel: +886-7-6577714 ext. 5352; fax: +886-7-6578914) \\ ${ }^{2}$ Zoology Division, Endemic Species Research Institute \\ No.1, Mingsheng East Rd., Jiji Township, Nantou County, Taiwan, R. O. C. \\ (tel: $+886-49-761331$ ext. 566; fax: $+886-49761$ ext. 583) \\ *Corresponding author \\ e-mail:mmskink@gmail.com
}

(Received $12^{\text {th }}$ Aug 2016; accepted $15^{\text {th }}$ Nov 2016)

\begin{abstract}
This paper analyzes data from the 2009-2016 projects for the removal of the invasive alien species Eutropis multifasciata from Green Island, Taiwan. In this study, the perimeter trapping method was used, and the validity of the method was verified at the beginning of the study. The result showed that the exponential regression analysis showed a statistically significant negative relationship between capture rate and time. Thus perimeter trapping was indeed an effective way of removing E. multifasciata. Besides, it investigates whether citizen action can assist in the removal of invasive alien species. The process of removal occurred in two stages; the first was funded by government, and the second involved citizen action. When citizens took over the work of removal, the size of the animals removed continued to decrease, as did the ratio of alien to indigenous individuals captured. In this case, introducing citizen action was an effective method of removing this invasive alien species.
\end{abstract}

Keywords: exponential decay model, eradication, civic ecology, community participation, volunteer tourism

\section{Introduction}

With the current changing environment, the effects of humans on the environment have become increasingly frequent, and the threat of invasive alien species (IAS) has become an important problem in the conservation of biodiversity (Bonanno, 2016). Past studies have found that IAS are one of the main reasons that species go extinct, second only to the destruction of habitats (Canadell and Mooney, 2002; Sharma and Raghubanshi, 2011; Wilcove et al., 1998). Furthermore, an island environment is more threatened by IAS than a mainland environment (Glen et al., 2013; Towns et al., 2013). In the last 500 years, three quarters of vertebrate extinctions and two thirds of plant extinctions have occurred on islands, and the primary factor in these extinctions has been the effect of IAS (Sax and Gaines, 2008). For example, in New Zealand, $70 \%$ of the mammals, $95 \%$ of the birds, and $90 \%$ of the reptiles have gone extinct (Keitt et al., 2011). Thus IAS can have a major effect on biodiversity in fragile island ecosystems. Moreover, Yiming et al. (2006) believes that since small islands have a lower biological resistance against IAS, IAS can easily establish a functional group and begin to spread.

Located on the western rim of the Pacific Ocean, Green Island is only $17 \mathrm{~km}^{2}$ in area. Human life was already present there 4000 years ago (Chan, 2009), but since the 
primary economic activity on the island changed from farming and fishing to tourism in the nineties, the frequent visits by tourists have increased the chances of alien species invading Green Island. The nineties of the $20^{\text {th }}$ century, past studies have shown that regardless of climatic zone, human travel is the primary method by which alien species are introduced (Anderson et al., 2015; Koutika et al., 2011). The common sun skink (the scincid Eutropis multifasciata, Kuhl 1820) was first discovered on Green Island in 2008, and is believed to have been introduced to the island via tourism (Chen et al., 2008).

E. multifasciata originates from Indochina and southeastern Asia (Uetz and Hošek, 2016). It was first found to have invaded the Kaohsiung region of Taiwan in 1992 (Ota et al., 1994), and presently occupies low altitude habitats in southwestern Taiwan. As E. multifasciata adapts easily to the environment, and preys on other lizards in its habitat, the populations of indigenous lizards in that area have declined sharply. The invasion of E. multifasciata on Green Island has received attention because it preys on the endemic species the scincid Plestiodon chinensis leucostictus and other indigenous lizards, threatening the island's biodiversity (Chao et al., 2009).

Simberloff (2009) has identified five factors crucial to the successful eradication of IAS: (1) swift action in the early stages of invasion; (2) the allocation of adequate resources to complete the project; (3) the cooperation of stakeholders with the institution responsible for the eradication; (4) adequate research into the background of the target species; and (5) energy, optimism, and persistence in the project leaders when facing occasional difficulties. Of these five factors, the greatest difficulty in this case is limited finances and human resources, which creates challenges in identifying an appropriate course of action to eradicate or suppress E. multifasciata. The removal of E. multifasciata from Green Island initially received a lot of attention from the government, and four years of financial support, but the funding provided was rather low relative to the generally high cost of IAS eradication operations. For example, California successfully eradicated the invasive Pacific alga Caulerpa taxifolia in two years, but this cost 7,000,000 USD (Simberloff et al., 2013). Such enormous expenditures are a severe challenge for Taiwan and many other countries around the globe. Past studies have shown that introducing a moderate level of citizen action, such as enlisting communities or volunteers help with the work, is a feasible approach to this problem (Dolan et al., 2015; Glen et al., 2013; Harvey et al., 2016; Kelehear et al., 2012; Moon et al., 2015). However, the specific mode of operation of citizen action will vary according to the characteristics of the community, so identifying the method that will result in the specific outcomes required is a key issue in the removal of IAS.

Cromarty et al. (2002) identified the following core principles for the removal of island IAS: (1) the method of removal must be feasible; (2) the rate of removal must be higher than that of population growth; and (3) there must be no new invaders. These principles have provided specific methods for removing IAS.

In this study we analyze data from the 2009-2016 removal of the IAS Eutropis multifasciata, with two primary investigative purposes. Firstly, we seek to investigate whether perimeter trapping, the initial method of capture, was effective in removing E. multifasciata. Secondly, we discuss whether introducing citizen action is sufficient to suppress E. multifasciata and stimulate the recovery of native lizards, since the government is unable to keep funding the removal. Because lizards do not usually pose an immediate hazard to humans or the environment, it is difficult to obtain 
resources for removing invasive lizards from IAS-eradication funding. There are thus few cases of successful eradication of invasive lizards. This study can provide a reference for such cases in future.

\section{Materials and methods}

\section{Study area}

Green Island is located on the western rim of the Pacific Ocean, off the southeastern coast of Taiwan $\left(22^{\circ} 38.40^{\prime}\right.$ to $22^{\circ} 41.16^{\prime} \mathrm{N} ; 121^{\circ} 27.15^{\prime}$ to $\left.121^{\circ} 31.20^{\prime} \mathrm{E}\right)$. The island's area is approximately 1700 ha. Presently, E. multifasciata mainly occupies the northwestern corner of the island, covering an area of 10 ha (including potentially occupied areas of the invasive species; Fig. 1).

Green Island has a subtropical monsoon climate. It is warm, humid, and windy all year. The average annual temperature is $23.5{ }^{\circ} \mathrm{C}$. There is mean annual rainfall is 2500 $\mathrm{mm}$ and there is no significant dry season. Prior to 1990, the inhabitants supported themselves by farming and fishing. However, since the enactment of government policy changes in 1990, Green Island has developed a tourism industry. The island has a population of 3,000, but receives 300000 visitors per year. This change did not only affect the island's economy, but also had a range of social and ecological effects (Chao, 2014a). Since tourism is presently Green Island's primary industry, it was suggested that the E. multifasciata eradication work could be integrated with the tourism industry. In this way, volunteer trips would be used to introduce off-island volunteers to helping to remove IAS, in addition to involving volunteers from the community.

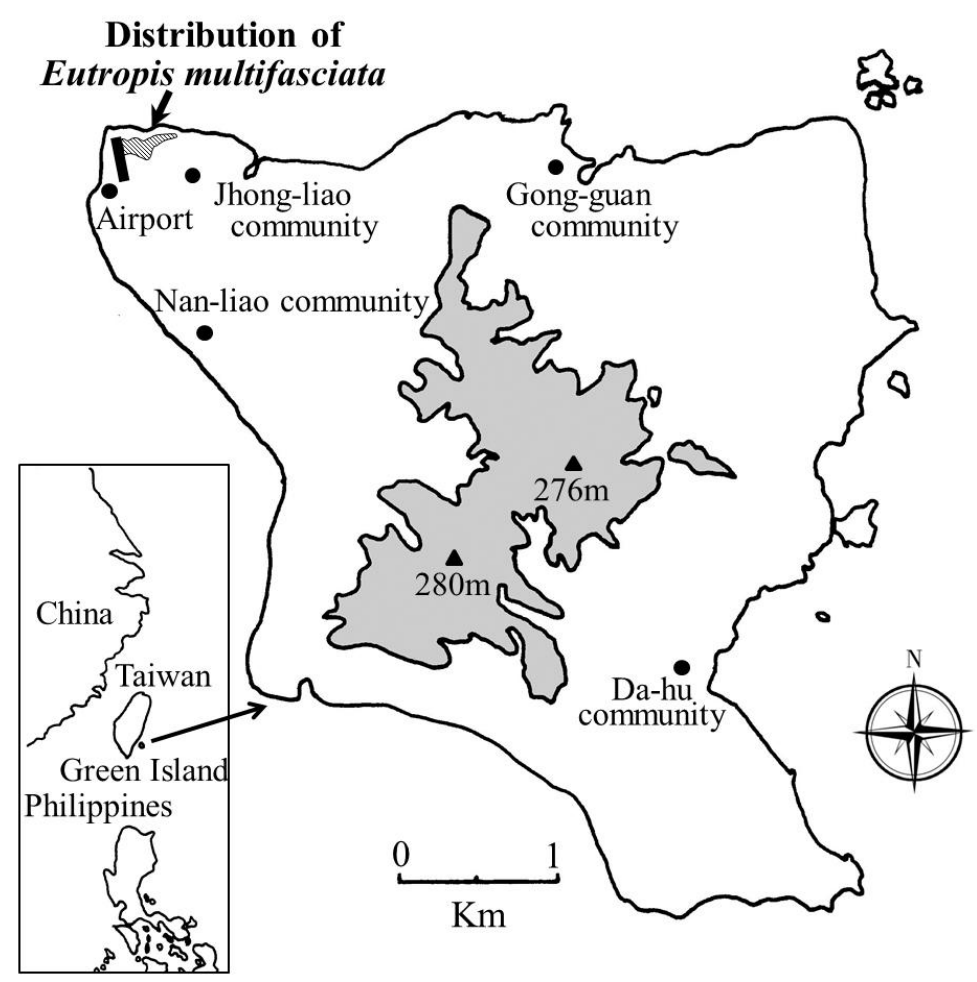

Figure 1. Distribution of Eutropis multifasciata on Green Island. The island's northwest corner (slanted line) is its primary range, which covers approximately 10 ha (including potentially occupied areas of the invasive species) 


\section{Data collection}

The period over which this study's data were collected is divided into two stages. The first stage, 2009-2012, was supported by government funding. From July 2009 to February 2010, perimeter trapping was used, mimicking that used for the removal of the invasive snakes (Boiga irregularis) on the Pacific island of Guam (Engeman and Vice, 2001; Engeman et al., 2000). But with the different of them, this study did not use any bait in our tarps. So that the traps were cost-effective and easily transportable, materials such as bamboo sticks, construction tape, and shrimp cages were used to construct 100 funnel traps, which were set around the perimeter of the forest. The traps were checked twice daily, at dawn and at dusk, to check that this trapping method was appropriate and to remove any animals caught. The indigenous lizards were be released immediately, but the E. multifasciata were be eradicated and took back to laboratory. Later March 2010 onwards, to improve the results, the construction tape was replaced with PP plastic boards. The boards were used to construct complete fences around the areas where the E. multifasciata had been found, and otherwise the methods remained unchanged. In addition, however, to assess the effect of the mass removal on the growth of the lizards, the snout-vent length (SVL) of each individual captured was measured.

The second stage, 2013-2016, was after the government had ceased subsidizing the project. The work of removing E. multifasciata was then done by the community and volunteer tourists. The first stage had been primarily conducted by researchers, but to compensate for the predicted cessation of funding, the community was encouraged to participate. In 2012, environmental education for the community was commenced, and interested volunteers from the community were recruited to learn the process, including species identification and removal methods. In 2013, then, these community volunteers took over the work of eradication. The methods used were the same as in the first stage, but community volunteers were limited. Although E. multifasciata is active throughout the year, indigenous lizards are most active from May to October (Chao et al., 2009), which coincides with the tourist season on Green Island, and the effort spent on the removal by local volunteers decreased as a result. The process was therefore designed to be a travel activity for tourists as well, and marketing mechanisms were used to bring in off-island volunteers to assist in the removal process.

All captured and removed E. multifasciata will be brought back to the laboratory, and to be measure the external morphology, including SVL, weight, gender etc. We dissected the contents of the stomach and checked the reproductive gland development, to determine whether the individual sexual maturity. Individual sexual maturity is judged on the basis of Auffenberg and Troy (1989) findings. They considered the individual, which the yolking ovarian follicles $>3 \mathrm{~mm}$ in ovaries, or oviductal eggs developing, was recorded as adult female. And the individual, which the seminiferous tubules were found to developed mature spermatozoa in the tissue sections of the testes, was recorded as adult male.

The capturing process is approved by the competent authority of the East Coast National Scenic Area Administration. We captured the E. multifasciata sent to the Endemic Species Research Institute to do research of permanent preservation. The indigenous lizards we captured were released in situ after recording the morphological data. 


\section{Data analysis}

Engeman et al. (2000) believed that an appropriate removal method would cause the capture rate to follow an exponential decay model. To assess whether the first-stage method (perimeter trapping) was successful, the capture rate was tested using exponential regression. And capture rate refers to lizards trapped divided by total trapdays. Later on, the change in SVL over time and the capture rate over time was analyzed using one way ANOVA and linear regression. The analysis was performed using SPSS 19 software.

\section{Results}

\section{Testing the results of perimeter trapping: exponential decay model}

To check that perimeter trapping was an effective method of removing $E$. multifasciata, data were collected for eight months, starting in July 2009. During this period, 349 animals were captured, of which 137 were juveniles (SVL: $52.75 \pm 1.06$ $\mathrm{mm}$ ), 120 were males (SVL: $91.35 \pm 0.88 \mathrm{~mm}$ ), and 92 were females (SVL: $91.62 \pm$ $0.93 \mathrm{~mm})$. The exponential regression analysis showed a statistically significant negative relationship between capture rate and time $\left(\mathrm{R}^{2}=0.695, p<0.01\right)$, and the regression curve fit the exponential decay model with the following equation: capture rate $=0.0105^{*} \exp \left(-0.1909^{*}\right.$ month) $($ Fig. 2). Thus perimeter trapping was indeed an effective way of removing $E$. multifasciata.

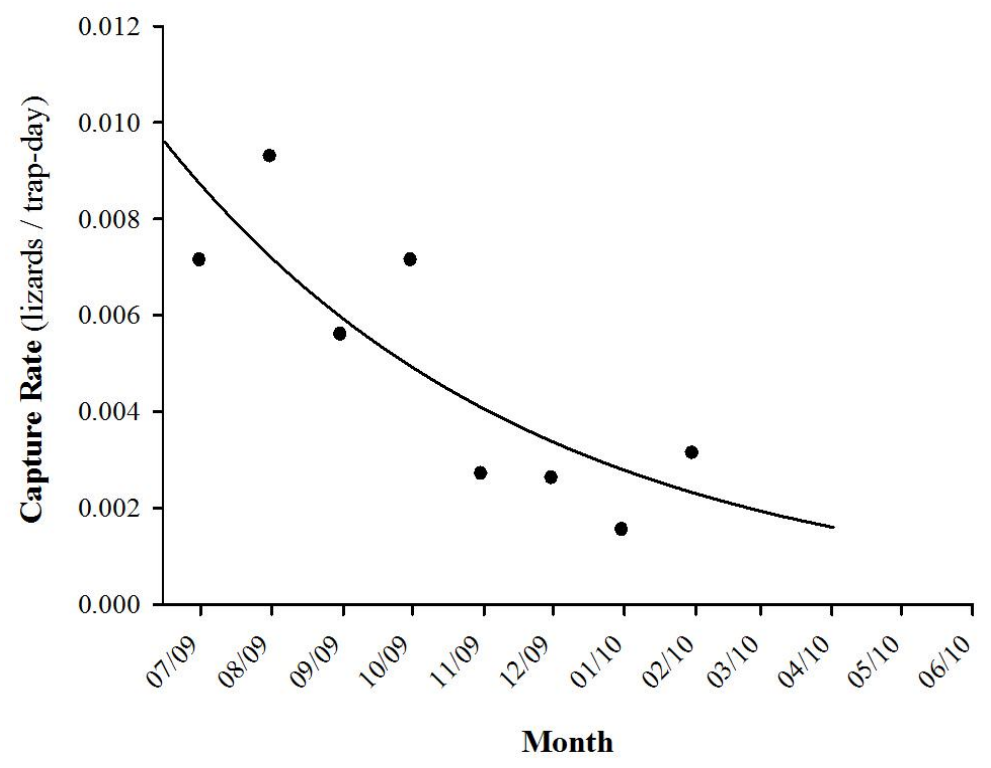

Figure 2. Change in capture rate of Eutropis multifasciata on Green Island when using perimeter trapping in 2009 and 2010. The capture rate fit the exponential decay model $\left(R^{2}=\right.$ $0.695, p<0.01)$.

In 2011, since the project was receiving funding from the government, effort was increased from 100 to 300 traps a day, to eradicate more IAS. As expected, the number of indigenous lizards trapped increased with the number of traps. This showed that the effectiveness of the perimeter trapping had not decreased over time (the lizards had not 
simply learned to avoid the traps). The capture rate of E. multifasciata continued to decline steadily, however, so its abundance was indeed decreasing as a result of the trapping.

Although the project was still receiving government funding in 2012, the amount of funding had decreased dramatically, suggesting that the government might cease to provide funding in the near to immediate future. A plan was therefore made for community volunteers to take over the task of controlling the E. multifasciata population. Since the lizards are most active in summer, which coincides with the tourist season on Green Island, the amount of time the volunteers could spend on the removal project was going to be limited. To decrease their workload, the amount of time spent on the project was cut in half (to 15 days a month, in the other 15 days the traps were be removed and when volunteers could join the traps would be set up again), although the number of traps remained at 300 . This was not ideal, since E. multifasciata would not be as tightly controlled, and the population might increase again (Table 1). Clearly, if using citizen participation to remove IAS, there would need to be an adequate number of volunteers. Since the numbers of community volunteers were insufficient, off-island volunteers were introduced. However, the people on Taiwan view Green Island as a far-off rural area, and convincing off-island volunteers to stay long-term was not going to be easy. Therefore, after considering the characteristics of the economy of the island, it was decided in 2013 that the removal project would be integrated into the tourism industry, creating a volunteer travel activity that would revolve around environmental education, to fill the volunteer deficit. In 2013, with the added human resources of the off-island volunteers, the number of traps was decreased to 200 and the trapping frequency reverted to daily.

Table 1. Number of removed Eutropis multifasciata on Green Island, 2010-2015 (including only data from March to October, when the lizards were most active)

\begin{tabular}{|c|c|c|c|c|c|c|}
\hline \multirow{2}{*}{ Removal information } & \multicolumn{3}{|c|}{ Government funding stage } & \multicolumn{3}{|c|}{ Citizen participation stage } \\
\hline & 2010 & 2011 & 2012 & 2013 & 2014 & 2015 \\
\hline Total effort (trap-days) & 36,750 & 73,500 & 36,750 & 49,000 & 49,000 & 49,000 \\
\hline No. indigenous lizards trapped & 626 & 1,542 & 490 & 726 & 976 & 1,001 \\
\hline $\begin{array}{l}\text { Capture rate of indigenous lizards } \\
\text { per } 100 \text { trap-days }\end{array}$ & 1.70 & 2.10 & 1.33 & 1.48 & 1.99 & 2.04 \\
\hline No. of E. multifasciata removed & 282 & 237 & 76 & 169 & 115 & 55 \\
\hline $\begin{array}{l}\text { Ratio of E. multifasciata to total } \\
\text { lizards trapped }(\%)\end{array}$ & 31.1 & 13.3 & 13.4 & 18.8 & 10.5 & 5.2 \\
\hline
\end{tabular}

\section{Analyzing the benefits of using community volunteers and volunteer tourism to assist with the removal of E. multifasciata}

\section{Change in Snout-vent length (SVL) over time}

From 2009-2016, the size of adult $E$. multifasciata decreased gradually (males: $\mathrm{R}^{2}=$ 2.543, $p<0.001$; females: $\mathrm{R}^{2}=6.712, p<0.05$ ) (Fig. 3). Although the individuals captured in 2015 were larger, the lizards captured the next year were smaller than those caught in 2014. Overall, regardless of sex, the size of adult E. multifasciata decreased 
with the mass removal of individuals from the population. This shows that because of the mass removal, E. multifasciata reached sexual maturity earlier, and their bodies thus became smaller. When community volunteers and volunteer tourists took over the removal work after government funding ceased in 2013, the SVL of mature male and female E. multifasciata continued to decrease, proving that citizen action can indeed suppress the population of this species.

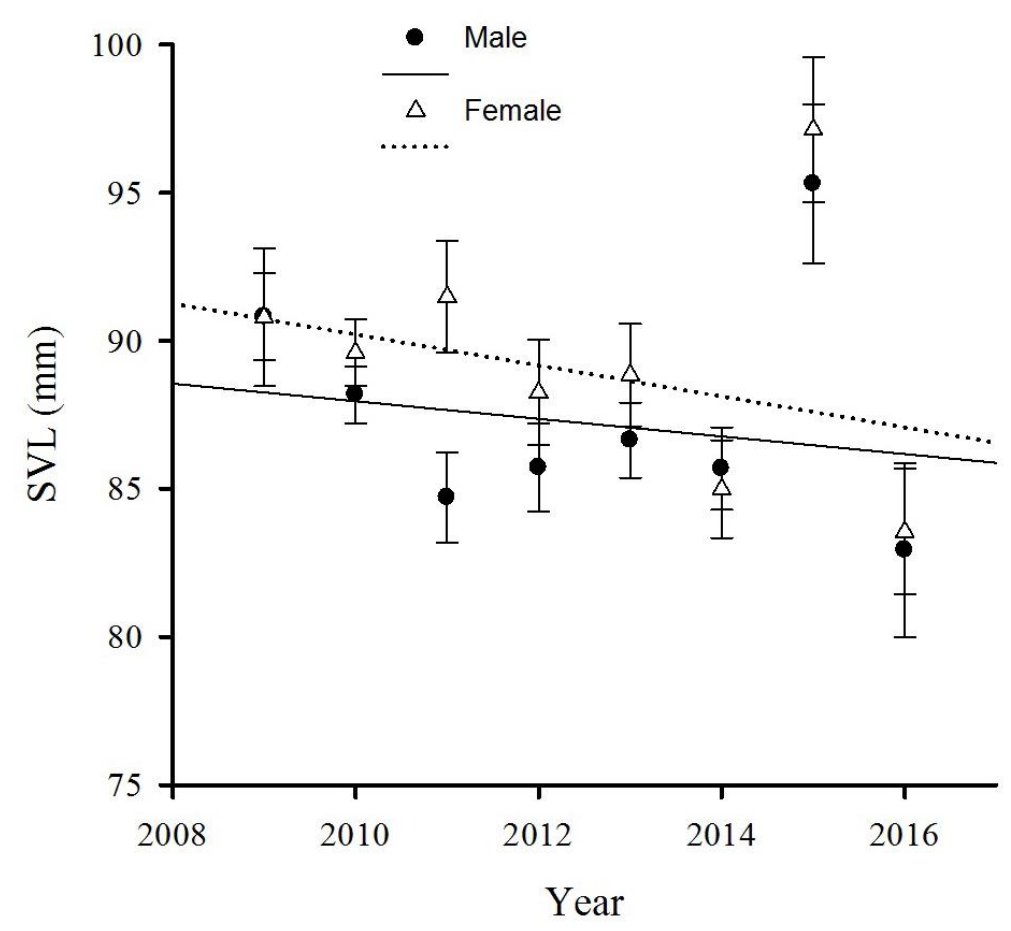

Figure 3. Change in mean annual snout-vent length (SVL) of mature male (closed circles, solid line; $p<0.001$ ) and female (open triangles, dotted line; $p<0.05)$ E. multifasciata on Green Island from 2009-2016.

\section{Recovery of native lizards}

The capture rate of E. multifasciata per trap over the years 2009-2015 decreased according to a strong $\left(\mathrm{R}^{2}=0.759\right)$ and statistically significant $(p<0.05)$ linear relationship: capture rate (no. lizards/trap-day) $=2.175-(0.00108 *$ year) (Fig. 4). Moreover, the proportion of E. multifasciata to total lizards trapped decreased from $31.1 \%$ in 2009 to $5.2 \%$ in 2015 (Table 1). This shows that when E. multifasciata was suppressed, recovery of the indigenous lizard populations can be assisted.

\section{Discussion}

\section{The importance of checking the stage of invasion by E. multifasciata}

Past studies have shown that IAS eradication is least costly and most likely to succeed in the early stages of the invasion (Carrion et al., 2011; Simberloff, 2003; 2009; Simberloff et al., 2013). An IAS invasion involves four stages: introduction, establishment, naturalization and spread/dispersal, and damage creation (Marbuah et al., 2014). Unless the IAS were intentionally introduced (e.g. for aquaculture, horticulture, 
or as pets), they are usually discovered between the first and second stages, although sometimes not until the third stage. However, if the IAS does not pose an immediate threat, policy-makers have to be convinced to devote resources to removing it (Burbidge, 2011). In the case of E. multifasciata, the government was persuaded to provide resources for its removal by proof that the invasion was still in its early stages, and the population was thus successfully suppressed.

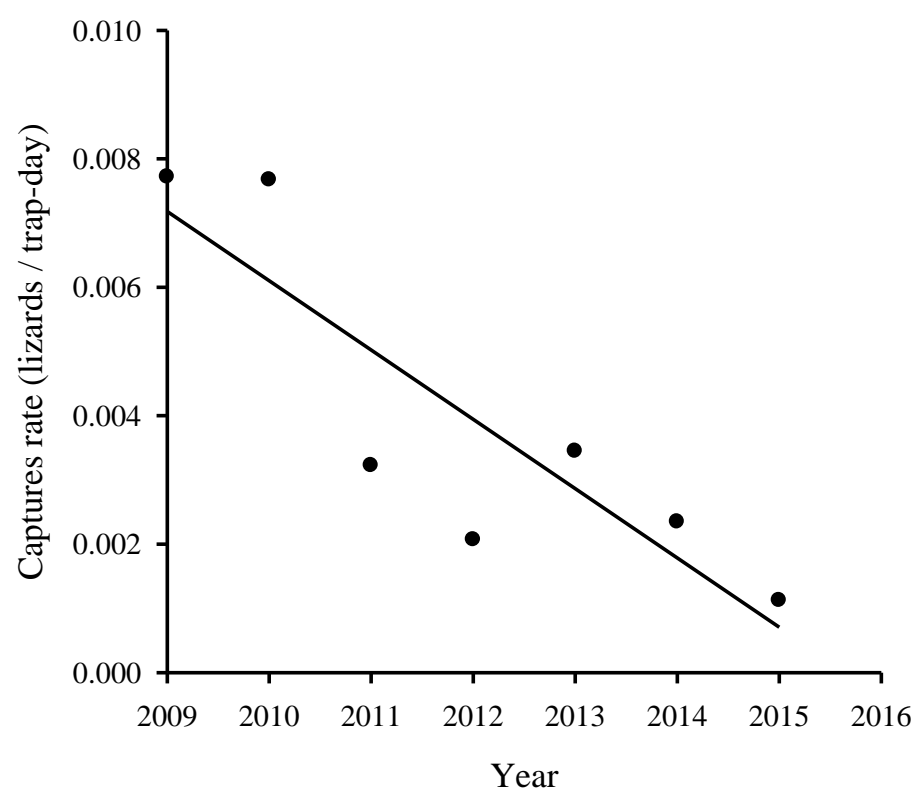

Figure 4. Average annual capture rate of E. multifasciata on Green Island from 2009-2015 ( $R^{2}$ $=0.759, p<0.05$ )

As to the means by which E. multifasciata arrived on Green Island, Wiles (2000) reported that this species was found in luggage on a plane travelling from the Philippines to Guam, when the plane arrived at Guam airport. The population of E. multifasciata on Green Island is located close to the airport runway, and since the island has a welldeveloped tourism industry, it is thought that the lizards arrived via tourist traffic.

However, how did we know that the species was in the early stages of its invasion when it was discovered in 2008? This question is important, for when IAS have become widespread, the funding required for their removal increases greatly, and the removal effort is less likely to succeed (Simberloff, 2009), which makes the government less likely to provide funding for the project. The reason why there is no such project for $E$. multifasciata on mainland Taiwan is that it has already become too widespread there, and it would be difficult to curb its further spread. To assess the stage of the invasion, it is necessary to assess two aspects of the population. First, the female: male ratio should be investigated. In the 2009 survey, this ratio on Green Island was 1: 2.18 (Chao et al., 2009). In contrast, the ratio on mainland Taiwan was 1: 12 (Chen and Lin, 2003). A reason for this difference might be that the group of E. multifasciata on Green Island was still in the early stages of invasion, and its sex ratio had therefore not yet stabilized. Secondly, the entirety of the area available to the IAS should be surveyed to find out where the invasive species is. E. multifasciata was found to occupy about 4 ha of the northwestern corner of Green Island, close to the airport. The potential area available to 
it (according to habitat suitability) is 10 ha (Chao et al., 2009). From these two findings, it was determined that E. multifasciata was still in the early stages of its invasion on Green Island.

\section{The contribution of scientific knowledge to the removal of E. multifasciata}

From a purely scientific viewpoint, the first thing to do in IAS removal is to ensure that the method used is feasible (Russell and Holmes, 2015; Towns et al., 2013). Engeman et al. (2000) believed that an effective removal method would result in an exponential decay model of the IAS capture rate, because over time an increasing proportion of the original population would have been removed. The removal effort on Green Island used perimeter trapping with funnel traps to remove E. multifasciata, and the curve of the capture rate fit an exponential decay model (Fig. 2), showing that this method was indeed effective. Although the amount of effort expended was later adjusted, the same capture method was still used, and the removal effort continued to succeed.

The contributions of scientific knowledge to this project include not only the assessment of the removal method, but more importantly, the education of the public and stimulation of citizen participation. Glen et al. (2013) believes that IAS removal on inhabited islands is even more important than on uninhabited islands, but also more difficult, because it is a challenge to get support from the inhabitants. Many island inhabitants do not understand the importance of IAS and the problems they cause, and this results in resistance during the removal process, which becomes the primary reason the removal fails (Moon et al., 2015). For example, during the E. multifasciata removal project on Green Island, most inhabitants could not tell the difference between the alien lizards and $P$. chinensis leucostictus, a subspecies endemic to Green Island, and initially believed that the project was damaging the environment by capturing $P$. chinensis leucostictus. Simberloff et al. (2013) stated that scientists have a duty to educate the public about IAS and resolve any misconceptions or doubts they have about them. In 2012, therefore, environmental education was provided through the school and the community, and as a result volunteers were recruited, which opened up the possibility of further citizen action in 2013.

\section{Evaluating the effects of removing E. multifasciata}

IAS removal is important, challenging work with ecological implications, and since it emphasizes effectively suppressing or eradicating IAS populations, assessing the effects of the removal effort is important. Evaluating the success of the project can be done in two ways. First, the size of the organisms can be measured. Hutchings (2004) compared the sizes of Atlantic cod captured in the sixties and the nineties, and found that because of overfishing (removal), the size of the fish had decreased significantly. This may have been the result of rapid evolution of the eggs, which may have increased in quantity but decreased in size when the population had decreased rapidly, and led to smaller fry (Heath et al., 2003). Although we have not analyzed the clutch size of $E$. multifasciata on Green Island, the effects of the removal project can be seen in the reduction in length of adults of both sexes (Fig. 3). From this we conclude that the removal method effectively suppressed the population of $E$. multifasciata.

Secondly, the success of the project can also be evaluated by assessing the recovery of the original ecosystem; after all, this is the desired end-result of a removal project. 
From the decreasing capture rate of E. multifasciata on Green Island (Fig. 4), we can see that the population was successfully suppressed. Moreover, the change in percentage of E. multifasciata of all lizards trapped (Table 1) dropped from $30 \%$ in 2009 to about $5 \%$ in 2016. This shows that the removal mechanism used did indeed suppress the population of E. multifasciata, and recovery of the indigenous lizard populations can be assisted (the capture rate of native lizards increased from 1.7 to 2.14 , Table 1).

\section{The value and operating mechanisms of citizen action in the removal of $E$. multifasciata}

In recent years, increasing numbers of studies have shown that citizen action has a positive effect on the removal of IAS (Dolan et al., 2015; Glen et al., 2013; Harvey et al., 2016). When considering the complications of removing IAS and the problems with obtaining the financial resources required for long-term monitoring, Simberloff (2009) suggested adding volunteer participation to plans for removing and managing IAS. There are many benefits to citizen participation in the removal of IAS, as can be seen from operations such as the project to remove Amur bush honeysuckle (Lonicera maackii) in Indiana, USA. Even if there are no actual benefits with respect to the success of the project, the volunteers learn about the effects of IAS; in other words, they receive environmental education through participation, as in the case of the removal of Burmese pythons (Python bivittatus) in Florida, USA (Harvey et al., 2016). Irrespective of the type of benefits seen, the participation of citizens contributes to the area's sustainability. Krasny and Tidball (2012) termed this type of citizen action "civic ecology", and suggested that these actions are "self-organized" by members of the community following a period of environmental and social deterioration. The problem is how to stimulate the participation of community members; is there any particular mechanism for encouraging community members to participate in IAS removal work? These are key issues in the process of this type of citizen action.

Regarding this question, Chao (2014b) proposed a conceptual framework for a "local intermediary organization", suggesting that when trying to encourage community participation, there must be a local organization that helps to uncover and solve social problems, introduce resources, and stimulate development. Chao (2015a) explained that for small, remote communities, the role of local intermediary organizations was even more important, since they could stimulate innovation in the community, reinvigorate the strength of the social force, and make long-term commitments to community sustainability. Simberloff (2009) has pointed out that one of the features needed for IAS removal to succeed is an optimistic and dedicated leader. This view is slightly amended in the conceptual framework in Chao (2014b), elevating the role of stimulating removal work from an individual to "institutions and organizations", since most IAS removal projects and the management thereof are lengthy and time consuming. Follow-up administration and monitoring is also crucial. With a local organization to shoulder this work, the removal and management of IAS can be sustained. To return to the case of the removal of E. multifasciata on Green Island: the organization that encouraged the community to participate was a local intermediary organization, The Society for Nature and Humanity. Since this organization had long been involved in community work on Green Island, they had won the inhabitants' approval, and could swiftly recruit local volunteers to participate in the removal project. 
Green Island is a tiny island with a population of 3000, and the amount of work community volunteers are able to contribute is limited, which is reflected in the results from 2013 (Table 1). Past research has found that using ecotourism to remove IAS and create economic benefits is a good management method for inhabited islands (Ogden and Gilbert, 2011; Samways et al., 2010). IAS removal work does not require a lot of technical knowledge, but does require a large workforce (Simberloff, 2009). For example, in this case, setting up and checking traps does not require a lot of knowledge, but even though it seems dull and repetitive, it is suitable as an activity for a volunteer trip (Chao, 2014a), and will attract volunteers. Moreover, volunteer trips are a form of sustainable travel (Dorin-Paul, 2013), which fits into Green Island's goal of sustainability. With the help of local intermediary organizations, the training of community volunteers, and marketing campaigns, Green Island has succeeded in attracting off-island tourists to help with the E. multifasciata removal work on themed trips. Currently, Green Island has over 3000 people participating in these trips each year (Chao, 2015b). The volunteer trips have not only succeeded in solving the labor problem the program faced after the government funding ceased, but has also brought economic benefits to community volunteers and encouraged them to keep participating.

Completely eradicating IAS is very difficult, but Simberloff (2003) suggests that, from a maintenance and management point of view, keeping IAS in an acceptable lowdensity state is sufficient. E. multifasciata on Green Island has not yet been eradicated, but the population is at a low density. Although the project received government funding in the beginning, the involvement of volunteers in the later stages of the project has been vital to its success. This mechanism will continue to play an important role in the follow-up monitoring and maintenance of E. multifasciata on Green Island.

Acknowledgements. This work first needs to thank the COA (Council of Agricuture) for its financial support. More importantly, many community volunteers, including staff of the Society for Nature and Humanity, and volunteer tourists to help, we were able to suppress the invasion species of Green Island.

\section{REFERENCES}

[1] Anderson, L. G., Rocliffe, S., Haddaway, N. R., Dunn, A. M. (2015): The role of tourism and recreation in the spread of non-native species: A systematic review and metaanalysis. - PloS one 10(10): e0140833. Available on: http://journals.plos.org/plosone/article?id=10.1371/journal.pone.0140833.

[2] Auffenberg, W., Auffenberg, T. (1989): Reproductive patterns in sympatric Philippine skinks (Sauria: Scincidae). - Bulletin of the Florida State Museum, Biological sciences 34(5): 201-247.

[3] Bonanno, G. (2016): Alien species: to remove or not to remove? That is the question. Environmental Science and Policy 59: 67-73.

[4] Burbidge, A. A. (2011): 2001 to 2010 and beyond: trends and future directions in the eradication of invasive species on islands. - In: Veitch, C. R., Clout, M. N., Towns, D. R. (eds.) Island Invasives: Eradication and Management. IUCN, Gland, Switzerland, New Zealand, 515-519.

[5] Canadell, J. G., Mooney, H. A. (2002): Biological and ecological dimensions of global environmental change. - In: Mooney, H. A., Canadell, J. G. (eds.) Encyclopedia of Global Environmental Change. John Wiley, Chichester, UK, 1-9.

[6] Carrion, V., Donlan, C. J., Campbell, K. J., Lavoie, C., Cruz, F. (2011): Archipelagowide island restoration in the Galápagos Islands: reducing costs of invasive mammal 
eradication programs and reinvasion risk. - PLoS One, 6(5), e18835. Available on: http://journals.plos.org/plosone/article?id=10.1371/journal.pone.0018835

[7] Chan, S.-C. (2009): Kuroshio and Sanasai legend: A Green Island's perspective. - Journal of Eastern Taiwan Studies 13: 75-94. (In Chinese)

[8] Chao, R.-F. (2014a): Volunteer tourism as the approach to environmental managementa case study of Green Island in Taiwan. - Journal of Environmental Protection \& Ecology 15(3A): 1377-1384.

[9] Chao, R.-F. (2014b): Innovation strategies of local intermediary organizations for environmental protection: a case study of Green Island, Taiwan. - International Journal of Organizational Innovation 7(2): 87-97.

[10] Chao, R.-F. (2015a): Effects of the transformation of social forces on environmental protection: An example of marine conservation in Green Island, Taiwan. - Revista de Cercetare şi Intervenţie Socială 50: 262-274.

[11] Chao, R.-F. (2015b): Development of slow tourism challenge and operation architecture: A case study on Green Island, Taiwan. - Acta Oeconomica 65(s2): 351-367.

[12] Chao, R.-F., Lin, T.-E., Lin, L.-K., Pei, K. (2009): The Survey and Remove of Invasive Alien Animals in Green Island. - Taitung County Government, Taitung, Taiwan. (In Chinese)

[13] Chen, P.-C., Chang, M.-H., Chen, S.-F., Li, Z.-L., Chen, S.-L., Lin, H.-C., Chu, C.-W. (2008): The Research of Terrestrial Vertebrate Fauna on the Green Island. - Marine National Park Headquarters, Kaohsiung, Taiwan. (In Chinese; with English abstract)

[14] Chen, Y.-L., Lin, T.-E. (2003): The Status of Invasive Reptile in Taiwan: The Ecology of Eutropis multifasciata. - Endemic Species Research Institute, Chichi, Taiwan. (In Chinese)

[15] Cromarty, P., Broome, K., Cox, A., Empson, R.A., Hutchinson, W.M., McFadden, I. (2002): Eradication planning for invasive alien species on islands - The approach developed by the New Zealand department of conservation. - In: Veitch, C. R., Clout, M. N. (eds.) Turning the Tide: the Eradication of Invasive Species. IUCN SSC Invasive Species Specialist Group, IUCN, Gland, Switzerland and Cambridge, UK, 85-91.

[16] Dolan, R. W., Harris, K. A., Adler, M. (2015): Community involvement to address a long-standing invasive species problem: Aspects of civic ecology in practice. Ecological Restoration 33(3): 316-325.

[17] Dorin-Paul, B. (2013). Sustainable tourism and its forms - A theoretical approach. Annals of Faculty of Economics 1(1): 759-767.

[18] Engeman, R. M., Vice, D. S. (2001): Objectives and integrated approaches for the control of brown tree snakes. - Integrated Pest Management Reviews 6(1): 59-76.

[19] Engeman, R. M., Vice, D. S., Nelson, G., Muña, E. (2000): Brown tree snakes effectively removed from a large plot of land on Guam by perimeter trapping. - International Biodeterioration and Biodegradation 45(3): 139-142.

[20] Glen, A. S., Atkinson, R., Campbell, K. J., Hagen, E., Holmes, N. D., Keitt, B. S., Parkes, J. P., Saunders, A., Sawyer, J., Torres, H. (2013): Eradicating multiple invasive species on inhabited islands: the next big step in island restoration? - Biological Invasions 15(12): 2589-2603.

[21] Harvey, R. G., Perez, L., Mazzotti, F. J. (2016): Not seeing is not believing: volunteer beliefs about Burmese pythons in Florida and implications for public participation in invasive species removal. - Journal of Environmental Planning and Management 59(5): 789-807.

[22] Heath, D. D., Heath, J. W., Bryden, C. A., Johnson, R. M., Fox, C. W. (2003): Rapid evolution of egg size in captive salmon. - Science 299(5613): 1738-1740.

[23] Hutchings, J. A. (2004): The cod that got away. - Nature 428(6986): 899-900.

[24] Keitt, B., Campbell, K., Saunders, A., Clout, M., Wang, Y., Heinz, R., Newton, K., Tershy, B. (2011): The global islands invasive vertebrate eradication database: A tool to improve and facilitate restoration of island ecosystems. - In: Veitch, C. R., Clout, M. N., 
Towns, D. R. (eds.) Island Invasives: Eradication and Management. IUCN, Gland, Switzerland, New Zealand, 74-77.

[25] Kelehear, C., Cabrera-Guzmán, E., Shine, R. (2012): Inadvertent consequences of community-based efforts to control invasive species. - Conservation Letters 5(5): 360365.

[26] Koutika, L. S., Rainey, H. J., Dassonville, N. (2011): Impacts of Solidago gigantea, Prunus serotina, Heracleum mantegazzianum and Fallopia japonica invasions on ecosystems. - Applied Ecology and Environmental Research 9(2): 73-83.

[27] Krasny, M. E., Tidball, K. G. (2012): Civic ecology: a pathway for Earth Stewardship in cities. - Frontiers in Ecology and the Environment 10(5): 267-273.

[28] Marbuah, G., Gren, I. M., McKie, B. (2014): Economics of harmful invasive species: A review. - Diversity 6(3): 500-523.

[29] Moon, K., Blackman, D. A., Brewer, T. D. (2015): Understanding and integrating knowledge to improve invasive species management. - Biological Invasions 17(9): 26752689.

[30] Ogden, J., Gilbert, J. (2011): Running the gauntlet: advocating rat and feral cat eradication on an inhabited island - Great Barrier Island. - In: Veitch, C. R., Clout, M. N., Towns, D. R. (eds.) Island Invasives: Eradication and Management. IUCN, Gland, Switzerland, New Zealand, 467-471.

[31] Ota, H., Chang, H. W., Liu, K. C., Hikida, T. (1994): A new record of the viviparous skink, Mabuya multifasciata (Kuhl, 1820) (Squamata: Reptilia), from Taiwan. Zoological Studies 33(1): 86-89.

[32] Russell, J. C., Holmes, N. D. (2015). Tropical island conservation: rat eradication for species recovery. - Biological Conservation 185: 1-7.

[33] Samways, M. J., Hitchins, P. M., Bourquin, O., Henwood, J. (2010): Restoration of a tropical island: Cousine Island, Seychelles. - Biodiversity and Conservation 19(2): 425434.

[34] Sax, D. F., Gaines, S. D. (2008): Species invasions and extinction: the future of native biodiversity on islands. - Proceedings of the National Academy of Sciences 105(Supplement 1): 11490-11497.

[35] Sharma, G. P., Raghubanshi, A. S. (2011): Lantana camara L. invasion and impact on herb layer diversity and soil properties in a dry deciduous forest of India. - Applied Ecology and Environmental Research 9(3): 253-264.

[36] Simberloff, D. (2003): Eradication-preventing invasions at the outset. - Weed Science 51(2): 247-253.

[37] Simberloff, D. (2009): We can eliminate invasions or live with them. Successful management projects. - Biological Invasions 11(1): 149-157.

[38] Simberloff, D., Martin, J. L., Genovesi, P., Maris, V., Wardle, D. A., Aronson, J., Courchamp, F., Galil, B., García-Berthou, E., Pascal, M., Pyšek, P., Sousa, R., Tabacchi, E., Vilà, M. (2013): Impacts of biological invasions: what's what and the way forward. Trends in Ecology and Evolution 28(1): 58-66.

[39] Towns, D. R., West, C. J., Broome, K. G. (2013): Purposes, outcomes and challenges of eradicating invasive mammals from New Zealand islands: an historical perspective. Wildlife Research 40(2): 94-107.

[40] Uetz, P., Hošek, J. (eds.) (2016): The Reptile Database. - Available on: http://www.reptile-database.org/.

[41] Wilcove, D. S., Rothstein, D., Dubow, J., Phillips, A., Losos, E. (1998): Quantifying threats to imperiled species in the United States. - BioScience 48(8): 607-615.

[42] Wiles, G. J. (2000): Recent records of reptiles and amphibians accidentally transported to Guam, Mariana Islands. Micronesica 32(2): 285-287.

[43] Yiming, L., Zhengjun, W., Duncan, R. P. (2006): Why islands are easier to invade: human influences on bullfrog invasion in the Zhoushan archipelago and neighboring mainland China. - Oecologia 148(1): 129-136. 